\title{
Cognitive technologies of art and design based on pastel palette of E. Degas in creating images of modern interiors
}

\author{
Vladislav Zhukov ${ }^{1, *}$ and Ekaterina Tugolukova ${ }^{1}$ \\ ${ }^{1}$ Saint Petersburg State University of Industrial Technologies and Design. Saint Petersburg, Russia
}

\begin{abstract}
The purpose of this study is to apply modern methods of metaphorical, simulation, and tabular modeling in creating images of design objects represented by visual-symbolic cognitive information dynamic systems (VKIDS) with locally stable structures (LUS) in the design of dominant modules of interiors and/or exteriors, modernist organizing human living space using cognitive technologies in the subject area of objects of plastic arts and design based on the representation of the pastel palette of E. Degas ' creativity.
\end{abstract}

\section{Introduction}

Modern cognitive sciences that develop the theory of design are an interdisciplinary approach, united by a post-non-classical research methodology [1,2] for the purpose of cognition, studying the patterns of acquisition, transformation, representation (representation [3]), storage, and reproduction of information.

Cognitive sciences widely use the methodology of the synergetic approach, which successfully describes the processes of self-organization [4,5]. . On the other hand, synergetics itself refers to the modeling of the cognitive systems of both the individual and collective cognitive processes. Therefore, there are grounds to talk about the formation of a cognitive-synergetic scientific program [6]. in the theory of design, that is, an approach based on the principles of modern nonlinear thinking, taking into account the trends in the development of modern interdisciplinary studies of cognition concerning the emergence of entities of the natural and human sciences [7].

The aesthetic principle in creativity always carries a quantum of unrestrained energy, containing macro-micro cosmic vibrations and rhythms [8] of morphology, coloristic, eidos, and concept in the images of works of plastic arts and design.

Human consciousness, constantly drawing and carefully looking at the world, divides its space with each drawn line, generating its harmony, a diverse manifestation of life in nature-whether it is the beauty of a wildflower, the running of horses, or the structure of a tree. This is how the first step into the big world of plastic arts is taken, and how the creative path to design begins through a better understanding and knowledge of the world. After all, art is primarily the education of the soul, the education of feelings, respect for

\footnotetext{
* Corresponding author: 1t_zhukova@mail.ru
} 
spiritual values. It not only reflects life but also shapes it, creates an idea of the beautiful, inspires the dream, makes the human soul richer. In our age - the age of unprecedented growth of the scientific and technical knowledge-the role of plastic arts and design is not decreasing, but increasing. Art teaches us to appreciate the individuality of the human person, it teaches compassion, sincerity.

Today, art is a communication tool in world culture [9]. People from different countries strive to get to know each other better, and culture and art provide invaluable help in this. But plastic arts and design are not limited only to the audience's delight and interest. They use their images to identify the eidos of conscience [10], stimulate thinking to an objective assessment of life's actions. This is their moral and moral significance [2]. The acidic content of a person should be restless, inquisitive, able to respond to someone else's pain and share the joy of others. The mental predestination of the design allows us to see its civic purpose in igniting hearts through emotions with truth, faith, love, and compassion [11].

\section{Materials and methods}

To create images of design objects represented by visual-symbolic cognitive information dynamic systems (VKIDS) with locally stable structures (LUS), when designing dominant modules of interiors and/or exteriors, modernists organize the living space of a person using cognitive technologies in the subject area of objects of plastic arts and design based on the representation of the pastel palette of creativity of the artist. Degas used modern methods of metaphorical, simulation, and tabular modeling in the development of cognitive technologies of plastic arts and design.

\section{Results}

The norm and the unattainable model-this can be attributed to the entire world of plastic art and design. The right guide in this will always be those works of artistic genius that have stood the test of time, which certainly includes the work of E. Degas (Fig. 1).

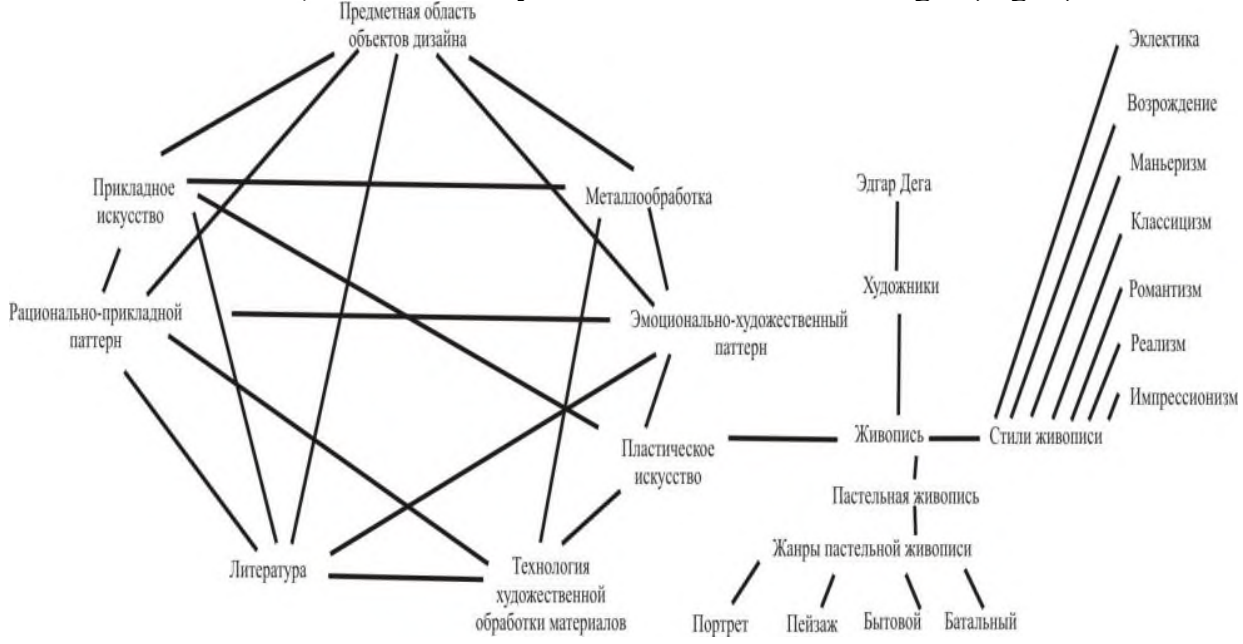

Fig. 1. The scheme of semantic reality in the pictorial work of E. Degas. Hypothetical scheme of structures of information and energy connections of universal complex spatial cyber-physical systems. 
In the process of studying the perfect forms of the works of E. Degas, not only a deep understanding of their content takes place, but we also join in thinking about those moral values that have remained as a historical heritage. This continuity of high ideals is the inseparable link between past and future generations. The memory of the past and its enduring values help to better understand today's life.

The deep involvement of life with culture gives a breadth of judgment, a true authenticity, which is so dear in art. Delving into the study of plastic arts and design, getting acquainted with the creative fate and life of E. Degas, there is a knowledge of the price, the work, and the search that always marked the path of a great master [12].

Unlike the rest of the Impressionists, he was an outstanding draughtsman and a talented amateur photographer. E. Degas used photography as one of the sources of inspiration. The most noticeable influence of photography was manifested in the composition of his canvases, for example, in the asymmetry and cropping of figures with the edge of the picture. In photography, such effects occur by accident, but in Degas ' paintings they are carefully checked and thought out. The cut-off figures and the blank areas left in the picture not only reject the generally accepted classical principles of composition but also help to create a sense of randomness, after which the whole picture looks like a slide, snatched by the gaze of real life.

One of the main tasks that the Impressionists set for Nepeg was to convey movement and an elusive moment, and Degas was not the only one who tried to give his painting the feeling of a snapshot. Some Impressionist paintings imitate the effect of motion captured by a photographic camera with a long shutter speed.

E. Degas always carefully thought out the composition of his paintings, often making many sketches and sketches.

Such methods involve precise calculation rather than freedom and inspiration, but they reflect only one side of Degas ' multi-faceted creative nature since in his creative quest he stands out as one of the most daring and original artists of his time. At the beginning of his professional career, Degas proved that he could masterfully paint in the traditional manner with oil on canvas, but in his mature years, he experimented extensively with various techniques or with a combination of materials. He often drew not on canvas, but on cardboard and used different techniques, such as oil and pastel, within the same picture, which showed a desire for creative experiment.

The artist's approach to engraving and sculpture was equally creative. Degas ' style was influenced by various artists. He deeply revered, for example, Ingres, and he considered himself a writer in the traditional manner that Ingres professed [13].

This influence is clearly visible in Degas ' early works-clear, classical in spirit, with clearly written forms. Like many of his contemporaries, Degas was influenced by Japanese graphics with their unusual angles, which he himself resorted to in his subsequent works [14].

The mature works of Degas are more individual, they assert that the drawing in painting is the basis of the basics, while Degas begins to care less about the beauty and clarity of the contour, expressing himself through a variety of forms and richness of color. This event coincided with Degas ' increased interest in pastels, which gradually became his main material for drawing. In pastels, the artist's approach becomes much bolder, and he uses color as freely as he used it when working with chalk or charcoal. Pastel really is on the borderline between drawing and painting, and Degas himself said that it allows him to become a "colorist with a line".

Pastel consists of a coloring pigment in powder, mixed with a small amount of an adhesive substance (usually gum arabic) and pressed in the form of chalk. Pastel can give a very rich and very weak tone, but it has a big drawback: the layer of pastel applied to the surface is extremely short-lived and can collapse at the slightest touch. 
Some of the leading Impressionist artists used pastels, appreciating their freshness of tone and the speed with which they could work.

Yet no one could match Degas's mastery of pastels, who used them with power and ingenuity that none of his contemporaries had ever achieved. Degas's style was characterized by amazing freedom, he applied pastels with bold, broken strokes, sometimes leaving a tone of paper showing through the pastels, or adding strokes of oil or watercolor. One of the artist's discoveries was the processing of the picture by steam, after which the pastel softened and it could be shaded with a brush or fingers. Degas not only used the pastel technique in a new way but also used it to create paintings that were larger than the works of other artists made in pastel. Sometimes he was made to do this together a few leaves to obtain the surface of a suitable size. In his recent pastels, made even when his vision was very weak, the majestic forms are almost completely dissolved in the fire of flaming colors [13].

In the end, Degas was able to develop his own unique view of the world around him. Table 1 shows the images of archetypes $[15,16]$ of the pastel trend of E. Degas ' creativity in the works of E. N. Tugolukova.

Tabular modeling allowed us to create interior designs "Inspiration and solitude" of residential premises of a country house (Fig. 2).
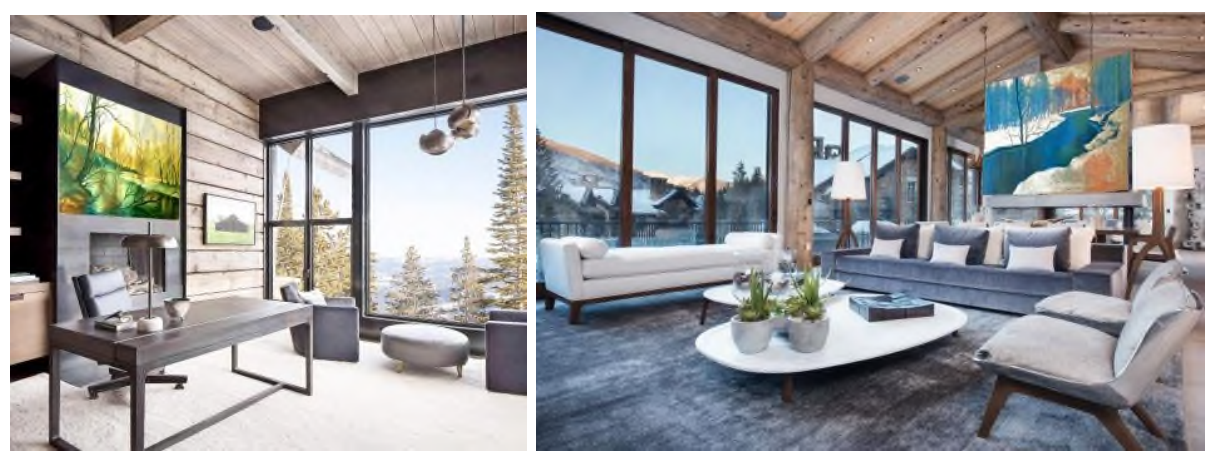

Fig. 2 Interior projects " Inspiration and solitude».

\section{Discussion}

The vital need of society for art and beauty, created in the creations of man and nature, forms in the most general sense the concept of evolution and harmonious development of the individual. The realization of this need thus becomes at the same time one of the peculiar moral, creative and intellectual beginnings of a person, activating his creative forces and abstract thinking.

Cognitive technologies cause society to gravitate towards natural nature, including when organizing its own life process in the historical retrospective of works of plastic art. In this work, the emphasis was placed on the painting and graphics of the French Impressionists.

\section{Conclusions}

The study was the analysis and synthesis of images of the archetypes from KIDS with LUZ in the application of cognitive technologies on the creative heritage of E. Degas and implemented a definite upgrade in the arrangement of the living space of a person. 


\section{Reference}

1. I.V. Melik-Gaikazyan, G.I. Petrova, N.A. Lukyanova, Myth, Dream, reality: post-nonclassical dimensions of the cultural space (Moscow, Scientific World, 2005).

2. A. Nazarethyan, Civilizational Crises in the context of Universal history (Moscow, Liters 2019)

3. O.E.Baksansky Cognitive representations: everyday, social, scientific (Moscow, LIBROCOM, 2016)

4. O. I. Glazunova Synergetics of creativity: Experience in the analysis of a literary text (Moscow, LIBROCOM, 2012)

5. O. E. Baksansky, E. N. Kucher The cognitive-synergetic paradigm of NLP: from cognition to action (Moscow, KRASAN D, 2010)

6. M. V. Kovalchuk Convergence of Science and Technology-a breakthrough into the future (Moscow, Znanie, 2010)

7. R. Steiner The Philosophy of Freedom. The main features of a modern worldview (Yerevan, Noi, 1993)

8. S. V. Nikonenko Eidos and concept. Epistemological foundations of symbolism in metaphysics, history, and art (Saint Petersburg, RHGA, 2017)

9. E. E. Moiseenko Encyclopedic Dictionary of the Young Artist (Moscow, Pedagogika, 1983)

10. D. Mannering. Life and creativity of Degas (Moscow, Spika, 1995).

11. E. V. Zavadskaya Culture of the East in the modern Western world (Moscow, Nauka, 1977)

12. K. G. Jung Soul and Myth. Six Archetypes (Kiev, State Library of Ukraine for Youth, 1996)

13. K. G. Jung Archetype and Symbol (Moscow Renaissance, 1991) 